\title{
Acute Panmyelosis with Myelofibrosis: A Rare Subtype of Acute Myeloid Leukemia
}

\author{
Alioune Badara Diallo*, Sokhna Aissatou Touré, Moussa Seck, Mouhamed Keita, \\ Elimane Seydi Bousso, Blaise Felix Faye, Saliou Diop
}

Hematology Department, Cheikh Anta Diop University, Dakar, Senegal

Email: *liounebd@gmail.com

How to cite this paper: Diallo, A.B. Touré, S.A., Seck, M., Keita, M., Bousso, E.S., Faye, B.F. and Diop, S. (2021) Acute Panmyelosis with Myelofibrosis: A Rare Subtype of Acute Myeloid Leukemia. Open Journal of Blood Diseases, 11, 81-87. https://doi.org/10.4236/ojbd.2021.113009

Received: August 1, 2021

Accepted: September 15, 2021

Published: September 18, 2021

Copyright $\odot 2021$ by author(s) and Scientific Research Publishing Inc. This work is licensed under the Creative Commons Attribution International License (CC BY 4.0).

http://creativecommons.org/licenses/by/4.0/

\begin{abstract}
Acute panmyelosis with myelofibrosis (APMF) is a subtype of acute myeloid leukemia (AML) classified among the category of "AML, not otherwise specified" in the WHO 2016 classification of hematopoietic tumors. It is a rare, fatal hematological neoplasm that is characterized by acute onset of cytopenias and bone marrow fibrosis in the absence of splenomegaly or fibrosis related morphological changes in the red blood cells. The difficulty of diagnosis and management explains why APMF is rarely reported in Africa. We report here the case of a 30-year-old man who presented with dizziness, palpitations and dyspnea. Diagnosis of APMF was retained on bone marrow histology and immunohistochemistry which showed bone marrow fibrosis and high cellularity with majority of myeloid blast cells. The patient was treated by low dose cytarabine monotherapy $30 \mathrm{mg} / \mathrm{m}^{2}$ per week. At 3 months of treatment, the patient was transfusion-independent, with normalization of hemoglobin and platelets counts. However, the death occurred after 8 months. This case highlights the diagnosis specificity and management of AMPF, knowing the number of potential differential diagnoses and difficulties of its therapeutic management.
\end{abstract}

\section{Keywords}

Acute Panmyelosis with Myelofibrosis, Bone Marrow Fibrosis, Cytopenias

\section{Introduction}

Acute panmyelosis with myelofibrosis (APMF) is a form of acute myeloid leukemia (AML) characterized by panmyeloid proliferation, increased blast cells, and bone marrow fibrosis. It is listed among the category of "AML, not otherwise specified" in the actual WHO classification of hematopoietic tumors [1]. The main characteristics are an acute onset of disease, pancytopenia and bone 
marrow fibrosis in the absence of splenomegaly or fibrosis-related morphological changes in red blood cells. It is a very rare disease entity accounting for approximately $1 \%$ of all AML cases. The clinical course is rapidly progressive with a median survival of $<1$ year in some reports [2].

Therefore, it is essential to make the accurate diagnosis and distinguish it from its mimickers, particularly acute megakaryoblastic leukemia (AML M7), chronic idiopathic myelofibrosis (CIMF) and AML with myelodysplasia related changes (AML-MRC) [3].

Prompt management and timely diagnosis can reduce morbidity and prolong survival.

However, accurate diagnosis of this condition is difficult in the context of sub-Saharan Africa where there are few specialists and limited access to diagnosis resources and treatment.

We present here a case of a 30-year-old male who presented with sudden onset of pancytopenia, diagnosed as APMF on bone marrow biopsy and treated with low dose cytarabine monotherapy. Other differential diagnoses considered are also highlighted.

\section{Case Description}

A 30-year-old male was referred to our unit for the investigation of anemia; the patient complained of a recent history of dizziness, palpitations and dyspnea on exertion. He did not mention any other symptoms such as fever or bleeding, and had no specific past medical story, including no medications. On examination, he was pale and tachycardic. There was no lymphadenopathy and no hepatosplenomegaly.

His complete blood count ( $\mathrm{CBC}$ ) revealed pancytopenia (Table 1). Peripheral blood smear showed macro platelets and anisopoikilocytosis, without circulating blast cells.

Serum parameters were normal, except an elevation of lactate dehydrogenase (LDH) $20 \times$ the upper limit of normal. Viral serologies (HIV, HCV, HBV) were negative.

Abdominal ultrasound revealed normal liver and spleen size, with no focal lesions.

A bone marrow aspirate was a "dry tap" and found to be hypocellular, without extra hematopoietic cells, which led us to perform a bone marrow biopsy.

The microscopic examination of the marrow biopsy showed nine osteomedullary spaces of high richness 5/5. The cell population was largely composed of blasts with large rounded or oval-shaped nuclei, fine chromatin, thick nuclear membrane and prominent nucleolus. The myeloid and erythroid lineages were dysplastic. The megakaryocytes were few increased. Bone marrow fibrosis grade 1 to 2 was present (Figure 1).

On immunohistochemistry slides, the majority of blasts expressed CD34. They showed negativity of lymphocyte and plasma cell markers as well as lymphoma markers and PS100 (Table 1). 


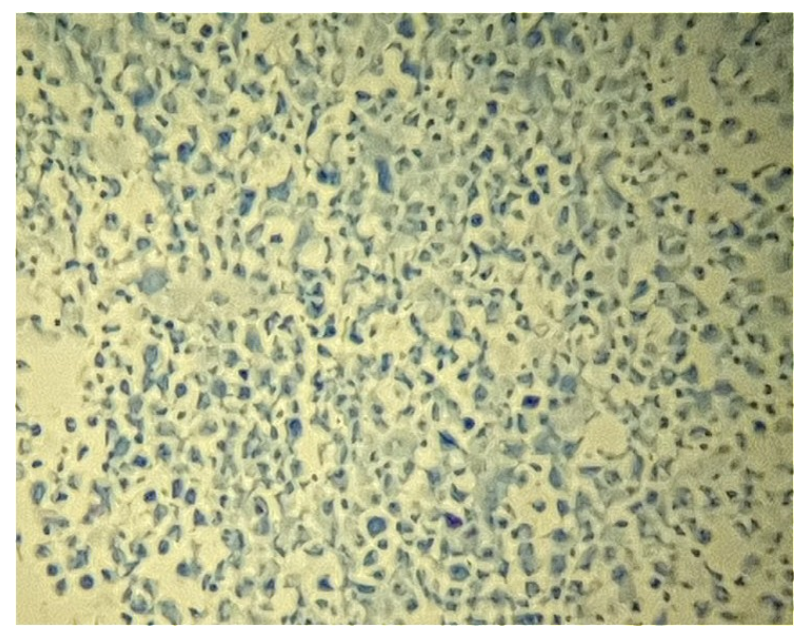

Figure 1. Bone marrow biopsy: hypercellular marrow with fibrosis and increased blast cells $(\times 400)$.

Table 1. Initial Laboratory Values of CBC, results of bone marry histology and immunohistochemistry.

\begin{tabular}{|c|c|c|c|}
\hline & Initial & Bone marrow Histology & Immunohistochemistry \\
\hline $\begin{array}{l}\text { Hemoglobin } \\
(\mathrm{Hgb})\end{array}$ & $37 \mathrm{~g} / \mathrm{L}$ & \multirow{5}{*}{$\begin{array}{l}\text { - High richness } 5 / 5 \\
\text { - Cell population largely composed } \\
\text { of blasts } \\
\text { - Dysplasia of myeloid and } \\
\text { erythroid lineages } \\
\text { - Few Increase of megakaryocytes } \\
\text { - Bone marrow fibrosis grade } 1 \text { to } 2\end{array}$} & \\
\hline $\begin{array}{l}\text { White blood } \\
\text { cells (WBC) }\end{array}$ & $2.25 \times 10^{9} / \mathrm{L}$ & & $\begin{array}{l}\text { - CD34+ } \\
\text { - Lymphocyte and plasma cell }\end{array}$ \\
\hline Neutrophils & $1.36 \times 10^{9} / \mathrm{L}$ & & $\begin{array}{l}\text { markers Negative } \\
\text { - Negativity of lymphoma }\end{array}$ \\
\hline Platelets (Plt) & $82 \times 10^{9} / \mathrm{L}$ & & markers and PS100 \\
\hline Reticulocytes & $16.6 \times 10^{9} / \mathrm{L}$ & & \\
\hline
\end{tabular}

The pathology favored a diagnosis of acute panmyelosis with myelofibrosis (APMF). Conventional cytogenetic analysis was not performed.

The patient underwent initially supportive care with transfusion of packed red cell and platelet concentrates. After staff concertation and evaluation of benefits versus risks, intensive chemotherapy induction regimen was not proposed due to severe cytopenias.

The patient was treated with low dose cytarabine monotherapy $30 \mathrm{mg} / \mathrm{m}^{2}$ per week subcutaneous.

After three months of treatment, there was an improvement in the general condition of the patient with transfusion independence. Control of $\mathrm{CBC}$ revealed increase of hemoglobin, platelets and WBC levels (Table 2).

The second bone marrow aspiration was successfully done (reduction of bone marrow fibrosis), showing a percentage of myeloblasts at 7.5\% (Figure 2).

The patient was followed up regularly by monthly appointments, with a clinical examination and a CBC at each check-up. At about six months of follow-up, $\mathrm{CBC}$ showed severe thrombopenia and anemia which needed transfusion of platelet concentrates and red blood cells.

However, he succumbed to death after eight months probably induced by intracranial hemorrhage due to severe thrombocytopenia. 


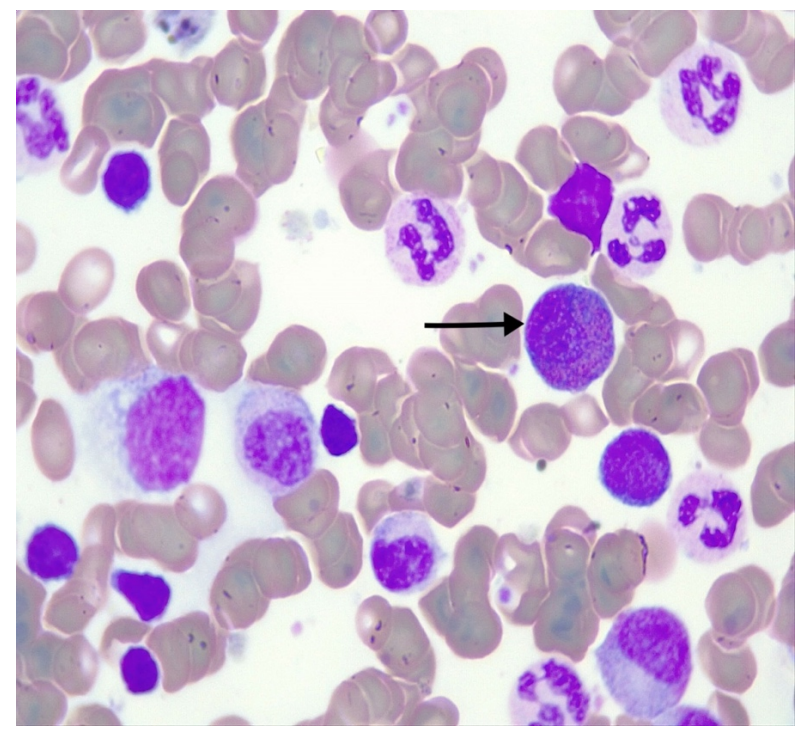

Figure 2. Second bone marrow smear showing myeloblasts (black arrow) $(\times 100)$.

Table 2. Control CBC after 3 months of low dose ARA-C.

\begin{tabular}{cc}
\hline Hemoglobin $(\mathrm{Hgb})$ & $140 \mathrm{~g} / \mathrm{L}$ \\
\hline White blood cells (WBC) & $3.32 \times 10^{9} / \mathrm{L}$ \\
Neutrophils & $1.40 \times 10^{9} / \mathrm{L}$ \\
Platelets (Plt) & $250 \times 10^{9} / \mathrm{L}$ \\
\hline
\end{tabular}

\section{Discussion}

APMF, previously referred to as acute myelofibrosis, acute myelosclerosis, or acute myelodysplasia with myelofibrosis, is a subtype of acute myeloid leukemia. At present, it is classified according to world health organization (WHO) under "AML, not otherwise specified" [1].

It represents $<1 \%$ of the cases of AML, although this may be an underestimation due to missed diagnosis. A literature search reveals few descriptive studies often revealed by acute onset of pancytopenia with the absence of splenomegaly and a rapidly fatal course [2] [4] [5]. To our knowledge, this is the first case reported in the literature in Africa.

Due to its poor prognosis and the number of hematologic malignancies which may lead to the same clinical picture, it is important to consider other differential diagnosis.

The primary differential diagnosis of APMF is acute megakaryoblastic leukemia (AML M7). These 2 entities share significant overlapping features, such as bone marrow fibrosis, unaspirable marrow, dysplastic megakaryocytes, and the presence of megakaryoblasts. However, in AML M7, megakaryoblasts comprise the predominant proportion of the blast population, whereas in APMF the majority of the blasts are of non-megakaryocytic origin [3].

The distinction between APMF and AML-MRC may be difficult. Both condi- 
tions lead to myelofibrosis with significant overlap. However, important clinical differences exist between these two entities, particularly the abrupt onset for APMF and its shorter survival rate in comparison with AML-MRC.

AML-MRC is a disease of the elderly with a median age of 60 years. It is defined in the WHO classification as an acute leukemia with the presence of $\geq 20 \%$ myeloid blasts in bone marrow and evidence of multilineage dysplasia, arising from previous myelodysplastic syndrome (MDS), or MDS-related cytogenetic abnormalities [1].

Differential with CIMF is usually much less problematic. CIMF is characterized by panmyelosis with intact maturation, progressive bone marrow fibrosis, and extramedullary hematopoiesis [6]. The presence of significant splenomegaly and characteristic peripheral blood changes such as leukoerythroblastosis, anisopoikilocytosis, and dacryocytes (tear drop cells) help in diagnosis.

In view of acute onset of symptoms, clinical and pathological findings, the diagnosis of APMF was retained in our patient after eliminating potential differential diagnoses.

In terms of management, there are no consensus standards for the treatment of APMF at the moment. A variety of therapeutic strategies have been employed. The most common course of action has been intensive chemotherapy with $3+7$ induction regimen which has produced remission [5] [7], rapidly followed by relapse.

Takaaki $\mathrm{K}$ et al. [8] studied the benefit of hematopoietic cell transplantation (HCT) in a retrospective analysis of 40 APMF patients in a Japanese registration between 2005 and 2015. This registry-based study confirmed that patients with APMF have a poor outcome due to high relapse rate even after syngeneic and allogeneic HCT. Other case reports have described the use of danazol and immunomodulatory drugs such as Thalidomide [3]. Vassilopoulos et al. [9] have reported a case of a 59 years woman treated with lenalomide with complete remission maintained for 3 years. Chatterjee et al. [10] reported a case of APMF in a 45 years male who was treated with " $3+7$ " induction by idarubicin and cytarabine; followed by three cycles of high-dose cytosine arabinoside after which was in complete morphological remission with markedly reduced bone marrow fibrosis.

A case report by Whitehead et al. showed the efficacy of low-dose ARA-C in reducing fibrosis and normalizing the peripheral cell counts in a middle-aged man with acute myelofibrosis [11].

In our case, intensive chemotherapy was not prescribed considering the severe cytopenias; low dose cytarabine monotherapy led to improvement of the general condition and reduction of the bone marrow fibrosis and cellularity. However, such treatment was not very successful due to occurrence of death eight months after the diagnosis.

\section{Conclusions}

APMF is a rare and aggressive form of AML under "AML NOS" by WHO 2016 
classification.

It needs to be identified early due to its poor prognosis. In a patient with abrupt onset of pancytopenia with no organomegaly and "dry trap" at bone marrow aspiration, the diagnosis should be kept in mind.

Management guidelines should be proposed for this subtype of AML in order to prolong survival of these patients.

\section{Conflicts of Interest}

The authors declare no conflicts of interest regarding the publication of this paper.

\section{References}

[1] Arber, D.A., Orazi, A., Hasserjian, R., Thiele, J., Borowitz, M.J., Le Beau, M.M., Bloomfield, C.D., Cazzola, M. and Vardiman, J.W. (2016) The 2016 Revision to the World Health Organization Classification of Myeloid Neoplasms and Acute Leukemia. Blood, 127, 2391-2405. https://doi.org/10.1182/blood-2016-03-643544

[2] Suvajdzic, N., Marisavljevic, D., Kraguljac, N., Pantic, M., Djordjevic, V., Jankovic, G., Cemerikic-Martinovic, V. and Colovic, M. (2004) Acute Panmyelosis with Myelofibrosis: Clinical, Immunophenotypic and Cytogenetic Study of Twelve Cases. Leukemia \& Lymphoma, 45, 1873-1879. https://doi.org/10.1080/10428190410001683688

[3] Gangat, N., Patnaik, M.M. and Zhang, B. (2014) Comparison of Acute Panmyelosis with Myelofibrosis and Acute Megakaryoblastic Leukemia: A Mayo Clinic Study. Blood, 124, 959. https://doi.org/10.1182/blood.V124.21.959.959

[4] Eric, T., Farah, M., John, B. and Maniate, J. (2010) Acute Panmyelosis with Myelofibrosis: An Unusual Cause of Pancytopenia. University of Toronto Medical Journal, 87, 153-154.

[5] Thiele, J., Kvasnicka, H.M. and Schmitt-Graeff, A. (2004) Acute Panmyelosis with Myelofibrosis. Leukemia \& Lymphoma, 45, 681-687. https://doi.org/10.1080/10428190310001625692

[6] Ahmed, A. and Chang, C.C. (2006) Chronic Idiopathic Myelofibrosis: Clinicopathologic Features, Pathogenesis, and Prognosis. Archives of Pathology \& Laboratory Medicine, 130, 1133-1143. https://doi.org/10.5858/2006-130-1133-CIM

[7] Slocombe, G.W. and Van Der Walt, J.D. (2006) Acute Panmyelosis with Myelofibrosis. Br J Haematol, 133, 66.

[8] Konuma, T., Kondo, T., Kawata, T., Iwato, K., Sato, Y., Mori, T., Ohashi, K., Nakazawa, H., Sugahara, H., Ago, H., Eto, T., Imamura, Y., Fukuda, T., Kanda, Y., Atsuta, Y., Yano, S. and Adult Acute Myeloid Leukemia Working Group of the Japan Society for Hematopoietic Cell Transplantation (2019) Hematopoietic Cell Transplantation for Acute Panmyelosis with Myelofibrosis: A Retrospective Study in Japan. Biology of Blood and Marrow Transplantation, 25, e23-e27. https://doi.org/10.1016/j.bbmt.2018.08.006

[9] Vassilopoulos, G., Palassopoulou, M., Zisaki, K., Befani, M., Bouronikou, E., Giannakoulas, N., et al. (2010) Successful Control of Acute Myelofibrosis with Lenalidomide. Case Reports in Medicine, 2010, Article ID: 421239. https://doi.org/10.1155/2010/421239

[10] Chatterjee, T., Gupta, S., Sharma, A., Sharma, S. and Gupta, D. (2013) Acute Pan- 
myelosis with Myelofibrosis-A Rare Subtype of Acute Myeloid Leukemia. Mediterranean Journal of Hematology and Infectious Diseases, 5, e2013042.

https://doi.org/10.4084/mjhid.2013.042

[11] Whitehead, S. and Geary, C.G. (1984) Low Dose Cytosine Arabinoside Used to Induce Remission in Acute Myelofibrosis. British Journal of Haematology, 58, 375-376.

https://doi.org/10.1111/j.1365-2141.1984.tb06097.x 